\title{
Response set effects in recognition memory*
}

\author{
MICHAEL C. CORBALLIS, CARLOS E. ROLDAN, and JANE ZBRODOFF \\ McGill University, Montreal, Quebec, Canada
}

\begin{abstract}
In three experiments, Ss responded to individual digits or letters according to whether or not each was in some prememorized list. There were either two possible responses (yes-no condition) or a single response (yes-only and no-only conditions). With memory sets of one, two, or four digits, RT was a linear function of memory set size. The slope of the function was least under the yes-only condition and greatest under the yes-no condition. Nonspecific practice had little effect on any of the slopes. With memory sets of 4,8 , or 12 letters, the slopes under the yes-only and yes-no conditions did not seem to differ, and practice with specific sets flattened the function considerably in both cases. Overall, the errors under the yes-no condition were mostly false alarms, those under the no-only condition mostly misses, and those under the yes-no condition were divided about equally. The results are interpreted partially in terms of a multiple-observations model of decision time.
\end{abstract}

It is well established that if a person must decide as quickly as possible whether or not a given item is a member of some recently memorized, arbitrarily chosen set of items, his response time (RT) will typically vary linearly with the number of items in the set. Sternberg $(1966,1969 b)$ has interpreted this to mean that the person rapidly compares the test item with each memorized item in turn. Since the slope of the RT function is about the same for positive as for negative items, the serial comparison process must be exhaustive rather than self-terminating; in other words, the person apparently continues to search the set even after he has "found" a match. The process of evaluating whether or not a match has occurred must, therefore, occur at some later stage. Sternberg (1969a) has in fact suggested that there may be at least four independent processing stages: encoding of the test item, serial comparison with the items of the memorized set, evaluation of the comparisons, and selection of the appropriate response.

One implication of the notion of independent stages is that factors which influence different stages should have additive effects on mean RT. However, Egeth, Marcus, and Bevan (1972) have reported a finding which, they claim, may be at variance with this principle of additivity. They varied the size of not only the memory set but also the response set; some Ss worked under a yes-only condition, in which they were to respond only to positive items, while others worked under the usual yes-no condition, in which they responded both to positive and to negative items. The slope of the RT function was less under the yes-only condition than under the yes-no condition. When the memory sets consisted of the digits in natural order (i.e., 1 and $1,2,3)$, the slopes were 2 and $35 \mathrm{msec}$ per digit, respectively; when they were more arbitrarily chosen (i.e., 1 and $1,4,7$ ), the slopes were 24 and $45 \mathrm{msec}$ per digit. One would expect variation in response set size to influence the response selection stage of processing,

*This research was supported by Grant 9425-10 from the Defence Research Board of Canada. while variations in memory set size presumably influence the serial comparison stage. Assuming these stages to be independent, therefore, one would expect memory set and response set variations to have additive effects on RT; yet the Egeth et al result clearly shows that they interact.

The present investigation examines the influence of response set on the RT function over a somewhat wider range of conditions. Egeth et al used only two different memory set sizes, so it is impossible to tell whether the yes-only condition merely produced a flatter RT function than the yes-no condition or whether it altered its shape as well. Consequently, in each of the three experiments reported here, we used three different memory set sizes. In the first two experiments, we also added a no-only condition, in which the Ss were instructed to respond only to negative items. Our object was to discover whether the Egeth et al result was due unambiguously to variations in response set size or whether it depended on some special property of the yes-only condition.

Finally, we examined the effects of practice on the RT function under the different response set conditions. Kristofferson (1972a) has reported that if Ss are given nonspecific practice, in which the memory sets are changed regularly in the course of practice, the overall RT decreases but the slope of the RT function remains constant, at least under the yes-no condition. But if Ss receive specific practice with the same memory sets, the RT function becomes progressively flatter (Kristofferson, 1972c; Ross, 1970). Ross noted, however, that the function does not flatten out completely, which appears to be at odds with a result reported by Neisser, Novick, and Lazar (1963). These authors had Ss search through long visual arrays of symbols to locate any one of a memorized set and reported that, if the Ss practiced extensively with the same sets, they could eventually search for 1 of 10 symbols as rapidly as they could search for a single one. Thus, with specific practice, visual search rate became 
Table 1

Percentages of Errors in Experiments $I$ and II

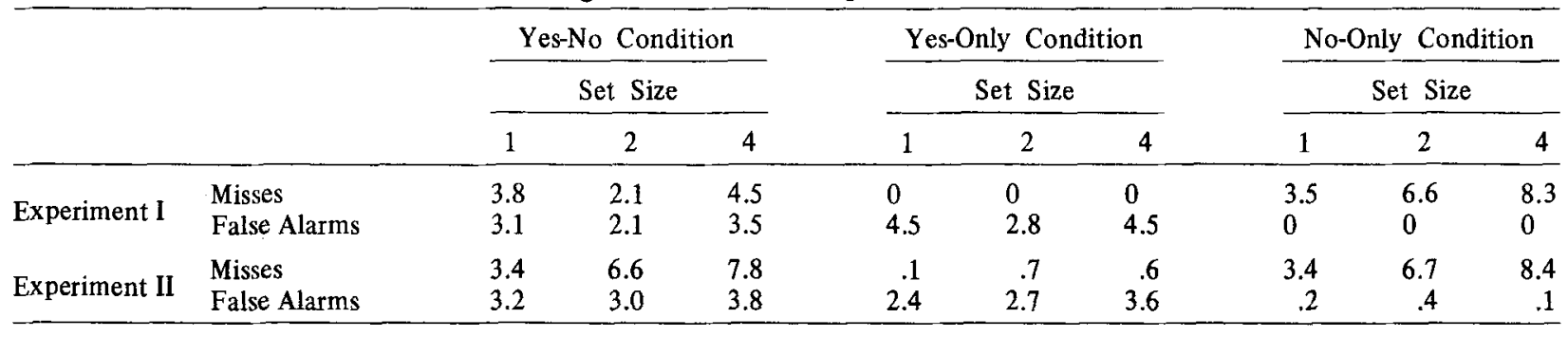

totally independent of memory set size. This discrepancy is perhaps not so critical as Ross thought, however, since several investigators have failed to reproduce the Neisser et al result, reporting instead that visual search rate does increase with memory set size even after prolonged practice with specific memory sets (e.g., Graboi, 1971; Kristofferson, 1972b). It has also been suggested that the Neisser et al result may be due to an artifact (Yonas \& Pittenger, 1973). Even so, we might note that all investigations of the effects of practice on the RT function have been restricted to the yes-no condition. The visual search task actually more closely resembles the yes-only condition, since the $\mathrm{S}$ has only to signal the positive item in each visual display. It therefore seemed of interest to determine whether practice would have different effects on the RT function under the different conditions.

\section{EXPERIMENT I}

This experiment simply compared RT functions for sets of one, two, and four digits under the yes-no, yes-only, and no-only conditions in a repeated-measurements design.

\section{Method}

Subjects. The Ss were six men and six women, all students, aged between 18 and 25 years.

Procedure. On any given session, the $S$ was first given a set of one, two, or four digits to remember. This was followed by a few demonstration trials, then by a series of 48 test digits, 24 of which had been included in the memorized set and 24 of which had not. Each digit was $3.53 \mathrm{~cm}$ high, projected on a digital display unit, and appeared white on a black background. A .5-sec warning tone came on $1.5 \mathrm{sec}$ before the onset of each test digit, which itself appeared for $150 \mathrm{msec}$. The warning tone for the next trial occurred $3.5 \mathrm{sec}$ later. The $S$ sat about $2 \mathrm{~m}$ from the display and could respond to each test digit by pressing a button with his index finger. Under the yes-only condition, he was told to respond only when the test digit was a member of the memorized set; under the no-only condition, he was to respond only when the test digit did not belong to the set. In these two conditions, he used the index finger of his preferred hand. Under the yes-no condition there were two buttons, and the $S$ had to push one with the index finger of one hand if the digit belonged to the set and the other button with the index finger of the other hand if it did not. Assignment of preferred and nonpreferred hands to the two buttons was counterbalanced over Ss. Between trials, the $S$ could rest his finger lightly on the button. The Ss were told to respond as quickly as possible consistent with a low rate of error.

Each $S$ worked for 3 consecutive days, receiving a different condition on each day. He also received all three set sizes on each day. The order in which the Ss received the set sizes was counterbalanced over Ss and over days. The order in which the conditions were assigned was also counterbalanced. This counterbalancing was orthogonal to that of the different ordering of set sizes, so the design constituted a Greco-Latin square.

The sets chosen for each $S$ on each day were nonoverlapping but otherwise randomly selected from the digits 0 through 9 . The test series were chosen so that the positive digits were distributed equally over the different serial positions of the memory set. The negative items exhibited response inconsistency (Kristofferson, 1972c); that is, an item that was negative on one series of trials could be positive on another. The test series were otherwise pseudorandomized to avoid obvious sequences or runs.

The Ss were given a few practice trials on the first session and additional practice on other sessions if they required it. Each $S$ was tested for recall of the memory set before and after each series of recognition trials. Recall was perfect in all cases.

\section{Results}

Errors. Percentages of errors are shown in Table 1. What is chiefly noteworthy about them is that there were no misses at all under the yes-only condition and no false alarms under the no-only condition. That is, the Ss erred only by pushing the button when they should not have and never by failing to respond when they should have.

Reaction Times. RT functions, computed for correct responses only, are shown in Fig. 1 . It is clear that the slope of the yes-only function is less than that of the no-only function and of both the "yes" and "no" components of the yes-no function.

Analysis of variance revealed a significant effect of memory set size $[F(2,12)=116.88, p<.001]$ and of positive vs negative decisions $[F(1,6)=33.59, \mathrm{p}<.01]$. There was also a significant interaction of Memory Set Size by Response Set Size (i.e., yes-no vs yes-only and no-only combined) $[\mathrm{F}(2,12)=4.01, \mathrm{p}<.05]$. The yes-only function was the principal contributor to this interaction (although the triple interaction between memory set size, response set size, and decision was not significant). Multiple two-way interactions showed that its slope was significantly less than that of the other three, whose slopes did not differ significantly. None of the functions departed significantly from linearity, and all were better approximated by a linear function of memory set size than by a logarithmic function.

\section{Discussion}

The results confirm and extend those of Egeth et al (1972). The RT function under the yes-only condition 
was clearly flatter than that under the yes-no condition. However, there was relatively little, if any, flattening of the function under the no-only condition, so the effect cannot be due simply to a reduction in response load. Further, there was no evidence that the RT function under the yes-only condition was altered in shape. All four functions shown in Fig. 1 are clearly linear.

\section{EXPERIMENT II}

In this experiment, the different response conditions were compared according to a between-Ss design. Each $S$ in fact worked with sets of one, two, and four digits on each of 18 days. However, the sets themselves differed from day to day, so the Ss became highly practiced at performing the task, but they did not receive extensive practice with particular sets. As noted earlier, Kristofferson (1972a) has reported that this kind of nonspecific practice results in an overall reduction in RT but no change in the slope of the RT function, at least under the yes-no condition. We wanted to know if the same would be true under the yes-only. and no-only conditions.

\section{Method}

Subjects. The Ss were eight men and four women, all students, aged between 18 and 25 years.

Procedure. The presentation of the stimuli and the response instructions under the different conditions were the same as in Experiment I.

Four Ss were assigned to each condition (yes-no, yes-only, and no-only) and worked under that condition for 18 days, consecutive except for weekends and occasional lapses. Each S received three new nonoverlapping but otherwise randomly selected digits every day. The order in which he received the different memory set sizes was counterbalanced over days, so that the $S$ received all possible orders every 6 days and a counterbalanced set of orders every 3 days.

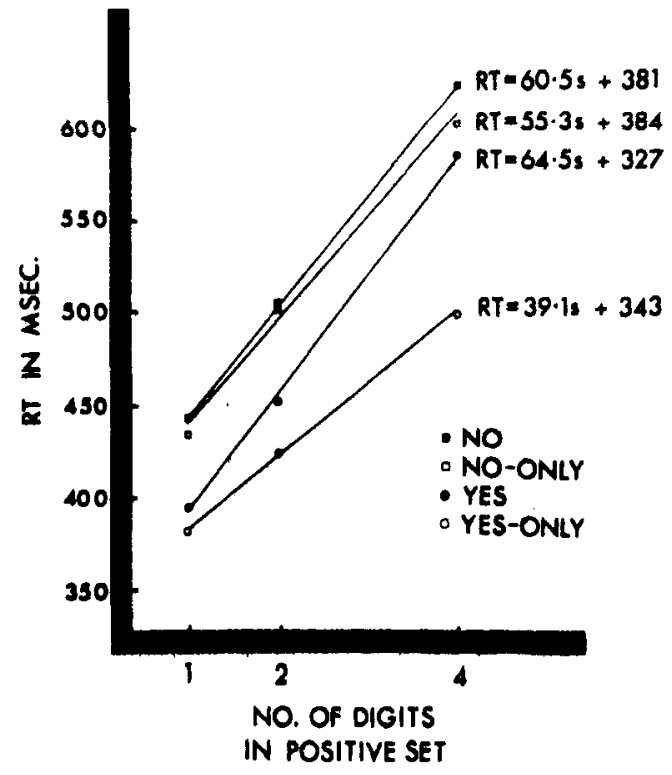

Fig. 1. Data points and least-squares linear functions for mean RTs in Experiment I.

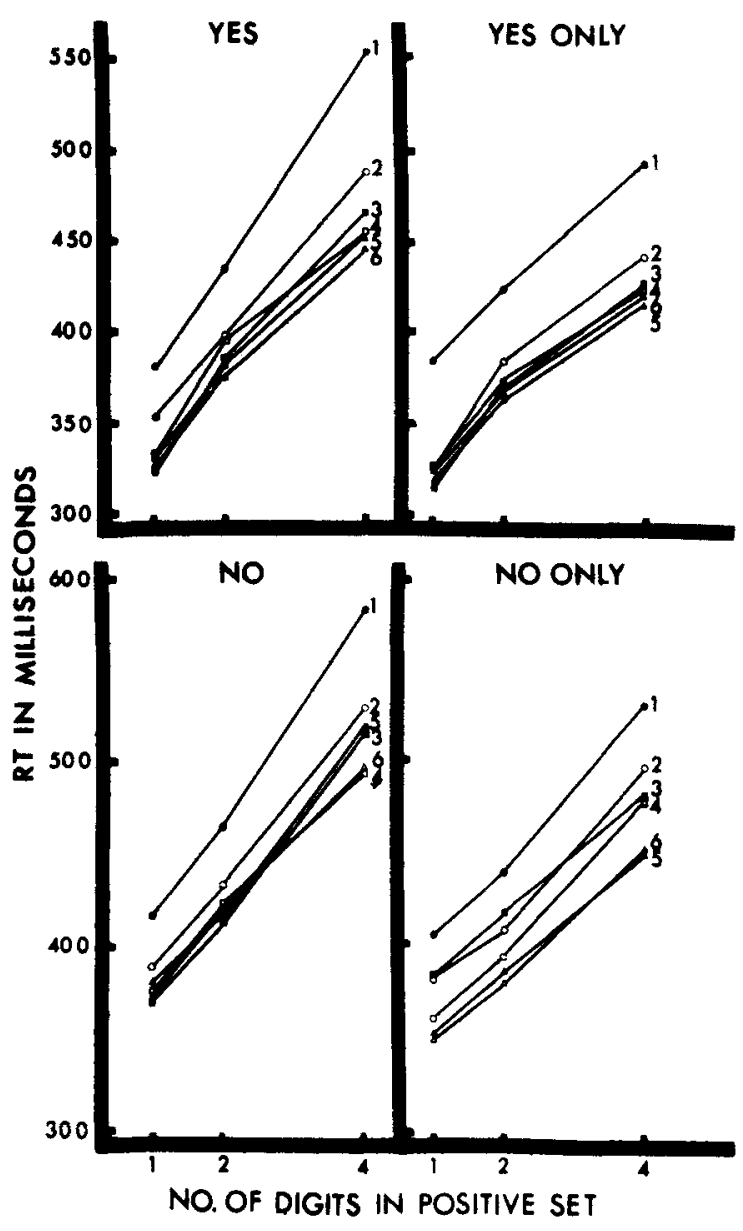

Fig. 2. Mean RTs plotted over 3-day blocks in Experiment II. Left panels represent the yes-no condition, right panels the single-response conditions.

Results

Errors. The percentages of errors are shown in Table 1. Again, under the single-response conditions the Ss usually erred by responding when they should not have rather than by failing to respond when they should have. However, response failures were not totally absent, as in Experiment I. Those that did occur may have resulted from failure to detect the test stimuli due to the attentional lapses. Each test stimulus was presented for only $150 \mathrm{msec}$, and the task proved increasingly tedious and boring over the 18-day period.

RT Functions. These were computed for correct responses only and were averaged over successive 3-day blocks of trials. Group means are plotted in Fig. 2. The data were analyzed in several ways.

First, RTs for "yes" responses under both yes-no and yes-only conditions were subjected to analysis of variance. The effect of memory set size was significant $[F(2,12)=334.59, \mathrm{p}<.001]$, as was the interaction between conditions and memory set size $[F(2,12)=$ $6.60, p<.05]$. Trend analysis revealed that this interaction was very largely due to the difference in linear trend; the interaction between conditions and the linear component of memory set size was significant 
$[F(1,12)=12.15, p<.01]$. Again, then, it is clear that the yes-only function sloped less than yes-no function. Least-squares estimates of the slopes were 34.1 and 44.9 msec per digit, respectively.

Although the overall effect of 3-day trial blocks on "yes" RTs was significant $[F(5,30)=14.62, p<.01]$, there was no reliable evidence that the slopes or shapes of the RT functions changed over the 18-day testing period. Trial blocks did not interact significantly with either conditions or memory set size, nor was the triple interaction significant. In none of the functions was there a significant deviation from linear trend. Even so, one can discern in Fig. 2 a slight flattening of the "yes" functions after the first trial block and something of a tendency, especially under the yes-only condition, for the functions to be negatively accelerated rather than linear. In fact, the RT functions under the yes-only condition were better fit by logarithmic functions of memory set size on all but the first trial block. The same was true of the yes-no function on Blocks 3, 4, and 5.

A second analysis of variance compared RTs for "no" responses under yes-no and no-only conditions. There were only two significant effects, one due to memory set size $[F(2,12)=192.97, \mathrm{p}<.001]$ and the other due to trial blocks $[\mathrm{F}(5,30)=7.05, \mathrm{p}<.01]$. The interaction between conditions and memory set size was not significant $[F(2,12)=2.79]$, although the slope of the RT function was in fact somewhat less under the no-only condition ( $36.6 \mathrm{msec}$ per digit) than under the yes-no condition (46.6 msec per digit). Both functions were linear rather than logarithmic on all trial blocks, and there was no evidence of any flattening of the functions over the 18 days of testing.

Third, analysis of variance of the RTs for yes-only and no-only conditions revealed a significant interaction between conditions and memory set size $[F(2,12)=$ $4.15, \mathrm{p}<.05]$. Trend analysis suggested that this was due to a difference in the shapes of the functions rather than in their slopes; the interaction between conditions and the linear component of memory set size was not significant $(F<1)$, but the residual was $[F(1,12)=8.3$, $\mathrm{p}<.01]$. As noted above, the yes-only function was better fit by a logarithmic function than by a linear one, while the no-only function was linear rather than logarithmic.

Finally, analysis of variance of the RT functions under the yes-no condition revealed that "no" RTs were significantly longer than "yes" RTs $[F(1,3)=140.19$, $p<.01]$. However, there was no significant interaction between decision and memory set size.

Serial-Position Effects. The analysis of RT functions suggested some tendency for RT functions for "yes" responses to be negatively accelerated rather than linear, especially under the yes-only condition. One possible explanation might be that the Ss did not always conduct an exhaustive search, especially if they encountered a positive item early in the search. This could have produced an overall shortening of RT for "yes" responses, especially for the four-digit sets. Assuming the Ss searched the sets in serial order, one would also predict a primacy effect, that is, shorter RTs for digits early in the set. However, there was little evidence for this. Serial-position effects were small, unsystematic, and insignificant for both two- and four-digit sets. This was true under both the yes-only and yes-no conditions and over all trial blocks.

\section{Discussion}

The results confirm Kristofferson's (1972a) finding that the slope of the RT function is little affected by nonspecific practice. This applies to the single-response conditions as well as to the yes-no condition.

The yes-only function was again clearly flatter than the yes-no function, confirming the results of Experiment $I$ and of the Egeth et al experiment. The no-only function was more ambiguous. It was flatter than the "no" component of the yes-no function but not significantly so. Had there been more Ss in the groups, a more reliable difference might have been obtained. However, both this experiment and Experiment I suggest that the effect of reducing response set is somewhat greater under the yes-only condition than under the no-only condition.

\section{EXPERIMENT III}

The final experiment investigated the effects of specific practice on the RT functions for both yes-no and yes-only conditions-the no-only condition was excluded. The Ss memorized sets of 4,8 , and 12 letters and worked with the same sets for 12 days.

As we noted in the introduction, two previous studies of the effects of specific practice on the RT function have found that the function does flatten out, but not completely (Kristofferson, 1972c; Ross, 1970). Both studies were somewhat unusual, however, in that the sets were nested and the test trials exhibited response consistency. Nested sets are those in which the smaller sets are included in the larger ones, and response consistency means that none of the positive items for any set ever appeared as a negative item for any other set. These conditions typically produce RT functions that are negatively accelerated rather than linear (see also Briggs \& Johnsen, 1973; Simpson, 1972). In the present experiment, half of the Ss worked with nested sets, while the other half worked with nonoverlapping sets. Response consistency, however, was not maintained.

\section{Method}

Subjects. The Ss were six men and six women, all university students, aged between 18 and 29 years.

Procedure. Presentation of stimuli and response instructions were basically the same as in the first two experiments. The letters were projected by means of a digital display unit and appeared white against a black background. Each letter was $3.53 \mathrm{~cm}$ high. 
Half of the Ss worked under the yes-no condition and half under the yes-only condition. The sets consisted of 4,8 , or 12 letters. The Ss thoroughly memorized the sets before the recognition trials and were tested for recall repeatedly throughout the experiment. They received 48 test trials, 24 positive and 24 negative, for each set every day for 12 days, consecutive except for weekends and occasional individual lapses. The order of presenting the different set sizes was counterbalanced over Ss and over days.

For half of the Ss within each condition the sets were nested from the beginning, so that the first 8 letters of the 12-letter list constituted the 8-letter list and the first 4 of the 8-letter list constituted constituted the 4-letter list. The letters were selected in blocks of four, so that individual letters were evenly distributed among the different set sizes. For example, three Ss would work with the same 12-letter set, but each $S$ received a different four-letter subset from it. The remaining Ss worked with nonoverlapping sets, and again the letters were circulated among the sets so that, overall, they were evenly distributed.

\section{Results}

Errors. Table 2 shows the percentages of errors. Again it is clear that false alarms dominated the errors under the yes-only condition.

RT Functions. RT functions for correct responses, averaged over 3-day blocks of trials, are plotted in Fig. 3 .

Analysis of variance of RTs under the yes-no condition revealed a significant interaction of Memory Set Size by Trial Blocks $[F(6,24)=7.49, p<.01]$, indicating that the RT functions did tend to flatten out with practice. The same interaction was also significant in the analysis of yes-only RTs $[F(6,24)=12.96$, $\mathrm{p}<.01]$. Under both conditions, the RT functions were flatter for nested than for unnested sets, although the interaction between nesting and memory set size was significant only under the yes-no condition $[\mathrm{F}(2,8)=$ 7.04, $\mathrm{p}<.05]$.

Oddly enough, there was no evidence from this experiment that the RT function was flatter under the yes-only condition than under the yes-no condition. If anything, the reverse seemed to be the case; the least-squares estimate of the slope of the overall RT function under the yes-only condition was $19.3 \mathrm{msec}$ per letter, compared with that of $13.2 \mathrm{msec}$ per letter for "yes" responses under the yes-only condition. However, analysis of variance of "yes" RTs failed to reveal a significant interaction between conditions and memory set size $[F(2,16)=2.73]$.

Table 2

Percentages of Errors in Experiment II

\begin{tabular}{|c|c|c|c|c|c|c|}
\hline & \multirow{2}{*}{\multicolumn{3}{|c|}{$\frac{\text { Yes-No Condition }}{\text { Set Size }}$}} & \multirow{2}{*}{\multicolumn{3}{|c|}{$\frac{\text { Yes-Only Condition }}{\text { Set Size }}$}} \\
\hline & & & & & & \\
\hline & 4 & 8 & 12 & 4 & 8 & 12 \\
\hline & \multicolumn{6}{|c|}{ Unnested Sets } \\
\hline \multirow[t]{2}{*}{ False Alarms } & $\begin{array}{l}3.5 \\
4.1\end{array}$ & $\begin{array}{l}7.5 \\
5.7\end{array}$ & $\begin{array}{r}9.0 \\
11.1\end{array}$ & $\begin{array}{r}.1 \\
3.7\end{array}$ & $\begin{array}{r}.2 \\
6.6\end{array}$ & $\begin{array}{r}1.0 \\
12.3\end{array}$ \\
\hline & \multicolumn{6}{|c|}{ Nested Sets } \\
\hline $\begin{array}{l}\text { Misses } \\
\text { False Alarms }\end{array}$ & $\begin{array}{l}5.6 \\
4.9\end{array}$ & $\begin{array}{l}5.3 \\
5.1\end{array}$ & $\begin{array}{l}7.6 \\
8.2\end{array}$ & $\begin{array}{r}.1 \\
3.8\end{array}$ & $\begin{array}{r}.2 \\
4.2\end{array}$ & $\begin{array}{r}.2 \\
5.8\end{array}$ \\
\hline
\end{tabular}

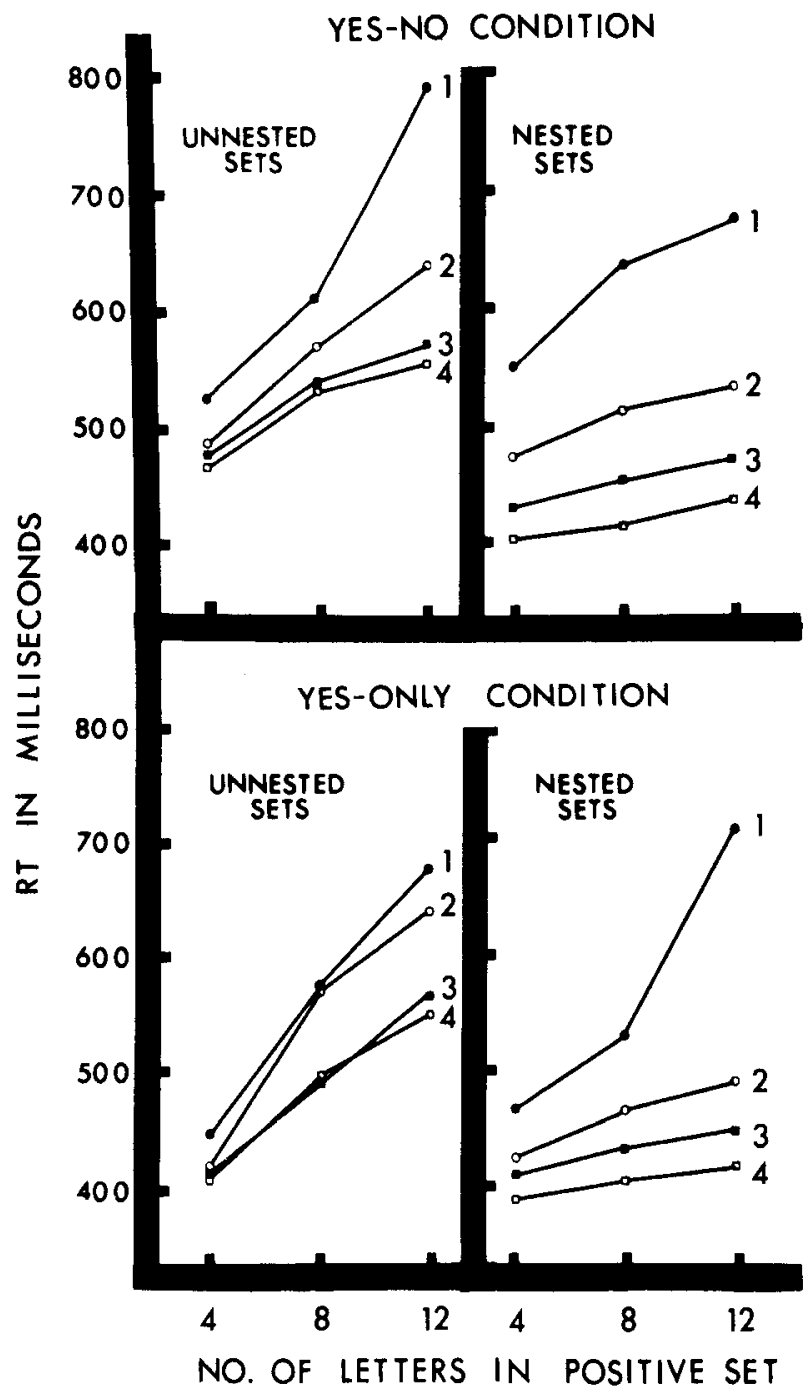

Fig. 3. Mean RTs plotted over 3-day blocks in Experiment III.

Table 3 shows the estimated slopes of the RT functions and error rates for each individual $S$ over the final 3-day block. Note that none of the functions flattened out completely, although two of them very nearly did so. Note also that there is at best only a rough negative correlation between slope and error rate. While S 5 made the most errors and showed the flattest RT function, S 11 made the fewest errors and still managed to show an RT function that was nearly flat. In short, flattening of the RT functions does not seem to have been obtained wholly at the expense of accuracy.

Although Fig. 3 indicates some variation in the shape of the RT functions, there was no reliable evidence that any of the functions departed from linearity. However, each point in the figure represents an average from only three Ss, and there were marked individual differences in this experiment.

Serial-Position Effects. It was important to examine serial-position effects in order to assess one possible explanation of why the RT functions were generally flatter for nested than for unnested sets. For each $\mathbf{S}$ 
Table 3

Estimated Slopes and Error Rates for Each Subject Over the Last 3-Day Block in Experiment III

\begin{tabular}{lcccc}
\hline Condition & $\begin{array}{c}\text { Type } \\
\text { of Set }\end{array}$ & S & $\begin{array}{c}\text { Esti- } \\
\text { mated } \\
\text { Slope* }\end{array}$ & $\begin{array}{c}\text { Percent } \\
\text { Errors }\end{array}$ \\
\hline \multirow{3}{*}{ Yes-No } & & 1 & 6 & 8.6 \\
& Unnested & 2 & 15 & 6.9 \\
& & 3 & 14 & 5.6 \\
& Nested & 4 & 10 & 6.7 \\
& & 5 & 2 & 11.3 \\
& & 6 & 2 & 6.7 \\
Yes-Only & & 7 & 19 & 2.3 \\
& & 8 & 21 & 6.0 \\
& & 9 & 14 & 6.7 \\
& & 10 & 4 & 4.6 \\
& Nested & 11 & 4 & .2 \\
& & 12 & 4 & 6.5 \\
\hline
\end{tabular}

*In milliseconds per letter

working with nested sets, the first 4 letters of each set were always the same, and the second 4 letters of the 8and 12-letter sets were also the same. There was no such repetition between the unnested sets. One might perhaps have expected the between-set repetition to produce a primacy effect for the 8- and 12-letter nested sets, which in turn might have flattened the function relative to that obtained with the unnested sets. However, serial-position analysis failed to reveal any such effect. In fact, there were slight but insignificant differences between RTs for each block of four letters, both for nested and unnested sets, and there was, if anything, more of a primacy effect for the unnested than for the nested sets. Therefore, the differences in RT functions between nested and unnested sets were not easily explained in terms of repetition.

\section{Discussion}

This was perhaps the least conclusive of the three experiments, perhaps because the longer memory sets and the use of letters rather than digits induced marked variations in the memorization strategies the Ss used. Nevertheless, it is remarkable that there was no evidence at all that the RT function was flatter under the yes-only than under the yes-no condition. Aside from this, the results confirm that practice with specific sets does produce a flattening of the function. However, they offer no support for the idea that the difference in response requirements might explain why practice can completely flatten the visual search function (Neisser et al, 1963) but only partially flatten the RT function. But, as we noted in the introduction, there is reason to question the Neisser et al evidence that the visual search function does flatten completely; in fact, more recent evidence suggests a close correspondence between the results of experiments of visual search and those on recognition time (e.g., Kristofferson, 1972c; Kristofferson, Groen, \& Kristofferson, 1973). The present experiment adds to this evidence by suggesting that the different response requirements in the two tasks are largely irrelevant.

\section{GENERAL DISCUSSION}

The experiments reported here provide some corroboration for the Egeth et al results. The yes-only function was clearly flatter than the yes-no function in the first two experiments, where the memory sets were subspan series of digits, but not in the third, where the memory sets consisted of series of 4,8 , or 12 letters. The slope of the no-only function appeared to lie somewhere in between; in Experiment I its slope was closer to that of the yes-no function; in Experiment II it was closer to that of the no-only function. There was little evidence that response set influenced performance in other ways. The effects of both specific and nonspecific practice were apparently the same under the different response set conditions, and there was no compelling evidence for differences in the shapes of the RT functions.

Egeth et al interpreted the interaction between memory set size and response set size as evidence for the nonindependence of processing stages. This interpretation depends on the implicit assumption that these two factors influence different stages-variations in memory set size influence the serial-comparisons stage and variations in response set size the response-selection stage. However, an alternative interpretation, which is still consistent with the idea of independent stages, is that the two factors influence a stage in common (cf. Sternberg, 1969a, p. 282). For example, it may not be unreasonable to suppose that variations in response set size influence the serial-comparisons stage as well as the response-selection stage. How might it do so?

One possibility is that the comparisons themselves are somehow simpler and, therefore, more rapid under the single-response conditions (particularly the yes-only condition) than under the yes-no condition. Under the yes-only condition, one might postulate that the S only records information about matches and ignores mismatches. He might perhaps bias his decision criterion in favor of detecting matches rather than mismatches, which could explain why the errors under this condition were predominantly false alarms. The converse reasoning does not apply so readily to the no-only condition, however, for if the $\mathrm{S}$ were to record only mismatches, he would have no basis for distinguishing positive from negative items. He might perhaps record both mismatches and matches but bias his detection criterion in favor of mismatches. This could explain why the errors consisted mostly of misses and why the RT function appeared to be somewhat steeper than under the yes-only condition (at least in Experiment I). Perhaps the main objection to this account, however, is that it implies that the reduction of one kind of error should be achieved at the cost of an increase in the other kind, but the data do not really suggest this to be so. In 
Experiments II and III at least, the percentages of false alarms were about equal under the yes-only and yes-no conditions, and in Experiment II the percentages of misses were about the same under the no-only and yes-no conditions. In Experiment I there was somewhat more evidence of compensatory increases in false alarms under the yes-only condition and in misses under the no-only condition, but the increases were still less than one would predict from a simple change in detection criterion.

Another possibility is that the process which gives rise to the linear RT function is not one of serial comparisons at all, but is simply one in which the elements of the memory set are serially primed, and that variations in response set somehow influence the rate of priming. The logical and empirical advantages of substituting the notion of priming for that of serial comparisons have been set nut elsewhere (Corballis, in press; Corballis \& Miller, 1973; Newell, 1973). The priming process would serve effectively to activate the elements of the set; the $S$ then has direct access to the internal representation of the test item and decides whether or not it is in a state of activation. However, it is perhaps not clear why the rate of priming should depend on response set. Corballis and Miller (1973) suggest that there may be a trade-off between rate of priming and degree of activation: the faster the priming, the weaker the activation. Under the single-response conditions, the decision process itself may be simpler and require less activation than under the yes-no condition, so that priming can be more rapid. But what, then, is the nature of the decision process?

Perhaps the most satisfactory account of the decision process is to be derived from a multiple-observations model proposed by Pike (1973). Under the yes-no condition, we assume the $S$ to make many observations of the strength of the test item in memory and to count the number of times he decides it to be positive or negative. When either count exceeds some criterion value, he makes the corresponding response. Under the yes-only condition, however, the $\mathbf{S}$ might ignore the negative decisions and count only the positive ones. This would explain why nearly all of the errors were false alarms; the S would hardly ever miss an item, since he would sooner or later reach the criterion for any item that was actually positive (provided he detects the item itself). Moreover, one would expect the number of false alarms to be about the same under the yes-only condition as under the yes-no condition, assuming the criterion count to be about the same in each case. Conversely, we might suppose that the $\mathrm{S}$ under the no-only condition counts only negative decisions. We would then expect his miss rate to be about the same as that under the yes-no condition, but his false alarm rate should be very low.

The multiple-observations model can, thus, readily account for the pattern of errors observed in our experiments. Other advantages of the model have been specified by Pike (1973) and by Corballis (in press). However, we still do not have a firm explanation for the variations in the slope of the RT function that are produced by variations in response set. One possibility is that the counting process tends to be more rapid when only one kind of decision is counted than when both "yes" and "no" decisions are counted. This might have a direct influence on the RT function, or it might mean that the $\mathrm{S}$ can afford to prime the memory set more rapidly and so operate on somewhat weaker traces under the single-response conditions than under the yes-no condition. This still does not explain why the RT functions under the no-only and yes-only conditions seemed to differ somewhat or why response set seemed to have no effect at all in Experiment III. However, it is perhaps idle to speculate further, given the rather inconsistent results.

There are in fact many variables which can influence the slope of the RT function, three of them illustrated in the present experiments. Experiments I and II demonstrated response set effects. Experiment III confirmed earlier evidence that practice with specific memory sets flattens the function and suggested that the function appears to be flatter when the sets are nested than when they are nonoverlapping. Corballis and Miller (1973) have reported data which suggest that the slope of the function may be sensitive to variations in stimulus and response probability. Sternberg (1969b) found a steeper function under a condition in which he inferred the $\mathrm{S}$ would have to retrieve the memorized set from long-term rather than short-term memory. Chase and Calfee (1969) report an increase in slope when the memory set and test item are presented in different modalities rather than in the same modality. Finally, there are wide individual differences even within any given set of conditions. Depending on the individual, his state of practice, and the conditions under which he is working, the slope of the RT function may range from about $2 \mathrm{msec} /$ item to something in excess of $100 \mathrm{msec} /$ item. We still know little about the mechanisms which underlie this remarkable variation.

\section{REFERENCES}

Briggs, G. E., \& Johnsen, A. M. On the nature of central processing in choice reactions. Memory \& Cognition, 1972, 1 , 91-100.

Chase, W. G., \& Calfee, R. C. Modality and similarity effects in short-term recognition memory. Journal of Experimental Psychology, 1969, 81, 510-514.

Corballis, M. C. Access to memory: An analysis of recognition times. In P. M. A. Rabbitt and S. Dornic (Eds.), Attention and performance $V$. New York: Academic Press, 1974, in press.

Corballis, M. C., \& Millex, A. Scanning and decision processes in recognition memory. Journal of Experimental Psychology, $1973,98,379-386$.

Egeth, H., Marcus, N., \& Bevan, W. Target-set and response-set interaction: Implications for models of human information processing. Science, 1972, 176, 1447-1448.

Graboi, D. Searching for targets: The effects of specific practice. Perception \& Psychophysics, 1971, 10, 300-304.

Kristofferson, M. W. Effects of practice on character-classification performance. Canadian Journal of Psychology, 1972a, 26, 54-60. 
Kristofferson, M. W. Types and frequency of errors in visual search. Perception \& Psychophysics, 1972b, 11, 325-328.

Kristofferson, M. W. When item recognition and visual search functions are similar. Perception \& Psychophysics, 1972c, 12. 379-384.

Krist of ferson, M. W., Groen, M., \& Kristofferson, A. B. When visual search functions look like item recognition functions. Perception \& Psychophysics, 1973, 14, 186-192.

Neisser, U., Novick, R., \& Lazar, R. Searching for ten items simultaneously. Perceptual \& Motor Skills, 1963, 17, 955-961.

Newell, A. Production systems: Models of control structures. In W. G. Chase (Ed.), Visual information processing. New York: Academic Press, 1973.

Pike, $R$. Response latency models for signal detection. Psychological Review, 1973, 80, 53-68.

Ross, J. Extended practice within a single-character classification task. Perception \& Psychophysics, 1970, 8, 276-278.
Simpson, P. J. High-speed memory scanning: Stability and generality. Journal of Experimental Psychology, 1972, 96, 239-246.

Sternberg, $S$. High-speed scanning in human memory. Science, $1966,153,652-654$.

Sternberg, S. The discovery of processing stages: Extensions of Donders' method. In W. G. Koster (Ed), Attention and performance II. Amsterdam: North Holland, 1969a.

Sternberg, S. Memory-scanning: Mental processes revealed by reaction-time experiments. American Scientist, 1969b, 57, 421-457.

Yonas, A., \& Pittenger, J. Searching for many targets: An analysis of speed and accuracy. Perception \& Psychophysics, $1973,13,513-516$.

(Received for publication November 28, 1973; accepted January 2, 1974.) 